Proceedings

\title{
Smart Sensing Fabrics for Live Bacteria Detection ${ }^{\dagger}$
}

\author{
Amparo Ferrer-Vilanova 1,*, Kristina Ivanova 2 ${ }^{2}$ María Díaz-González ${ }^{1}$, Yasmine Alonso ${ }^{3}$, \\ Gonzalo Guirado ${ }^{3}$, Tzanko Tzanov ${ }^{2}$ and Xavier Muñoz-Berbel ${ }^{1}$ \\ 1 Institut de Microelectrònica de Barcelona IMB-CNM-CSIC, Universitat Autònoma de Barcelona, \\ Cerdanyola del Vallès, 08193 Barcelona, Spain; maria.diaz@imb-cnm.csic.es (M.D.-G.); \\ xavier.munoz@imb-cnm.csic.es (X.M.-B.) \\ 2 Group of Molecular and Industrial Biotechnology, Department of Chemical Engineering, \\ Universitat Politècnica de Catalunya, Terrassa, 08222 Barcelona, Spain; kristina.ivanova@upc.edu (K.I.); \\ tzanko.tzanov@upc.edu (T.T.) \\ 3 Departament de Química Universitat Autònoma de Barcelona, Bellaterra, 08193 Barcelona, Spain; \\ yasmine.alonso@e-campus.uab.cat (Y.A.); gonzalo.guirado@uab.cat (G.G.) \\ * Correspondence: amparo.ferrer@imb-cnm.csic.es; Tel.: +34-935-947-700 \\ † Presented at the Eurosensors 2018 Conference, Graz, Austria, 9-12 September 2018.
}

Published: 27 November 2018

\begin{abstract}
A smart textile for live bacteria detection of antimicrobial hospital tissues is here proposed. The capacity to detect viable bacteria is based on the use of Prussian Blue (PB) as electrochromic compound, with a clear reversible change of colour from PB to Prussian White (PW) after reduction from a bacterial metabolism process. PB nanoparticles are incorporated to polyester cotton fabrics by ultrasonic deposition. After performing different tests with bacterial samples of $E$. coli and $S$. aureus, a full colour change of the textiles was observed. These smart textiles will allow to determine the self-life of the antibacterial compounds as well to improve the control of hospital infections.
\end{abstract}

Keywords: smart textiles; live bacteria detection; Prussian Blue; electrochromic compounds

\section{Introduction}

Nosocomial or hospital-acquired infections (HAI) are infections that the patient acquires in the hospital due to contaminated equipment, bed linens or air droplets, among others [1]. In an attempt to minimize the number of HAI, antibacterial textiles have been developed by incorporating bactericidal compounds in the textile. However, these textiles progressively lose their antibacterial activity with time, increasing the risk of contamination and infection.

From the myriad of strategies to detect bacteria, those based on DNA strains (DNA-sensors) [2] or antigens/antibodies (immune-sensors) [3] are not appropriated since DNA and antigens are very stable and may be present in the textile long after bacterial colonization. Alternatively, metabolic indicators are molecules that only change when they are in contact with live bacteria [4]. Concretely, bacteria metabolizes the compound producing a change in conductivity, $\mathrm{pH}$ or colour. In defined substrate technology, colourless substrate is selectively metabolized by bacteria, which allows identification. However, their application is limited to natural environments due to the heterogeneity of the bacterial population. Alternatively, a number of electrochromic compounds, which present a different colour for the oxidized and the reduced forms, have demonstrated capacity to act as final electron acceptors in the electron transport chain, as some electrochromic molecules [5]. This is the case of Prussian Blue (PB). This colour change capacity is here exploited for the development of a smart textile sensitive to the presence of living bacteria with the ultimate goal of being implemented in antibacterial tissues for shelf-life determination. 


\section{Materials and Methods}

\subsection{Prussian Blue Deposition}

Prussian Blue nanoparticles were deposited into polyester cotton textiles by a ultrasound coating process. Textile samples $(3 \times 3 \mathrm{~cm})$ were immersed in a solution of Prussian Blue $0.25 \mathrm{mM}$ and were sonicated with a frequency of $37 \%$ at $20{ }^{\circ} \mathrm{C}$ during three different period of times $(5,15$ and $30 \mathrm{~min})$.

\subsection{Bacterial Assays}

Polyester cotton fabrics modified with Prussian Blue $0.25 \mathrm{mM}$, were incubated with bacterial samples of Escherichia Coli (E. coli) and Staphylococcus Aureus (S. aureus), with $5.7 \times 10^{10}$ and $5.9 \times 10^{10}$ $\mathrm{CFU} / \mathrm{mL}$, respectively, during $24 \mathrm{~h}$, in a phosphate buffer solution with $0.1 \%$ of glucose. For the textiles with deposited antimicrobial nanoparticles, the same procedure was used.

\section{Results and Discussion}

PB molecules were susceptible to microbial reduction by bacterial metabolism electron transfer processes. According to the scheme presented in Figure 1 in the electron transport chain of E. coli, the redox potential of $\mathrm{PB}$ was small enough to interact with many of the proteins and mediators present there being reduced.

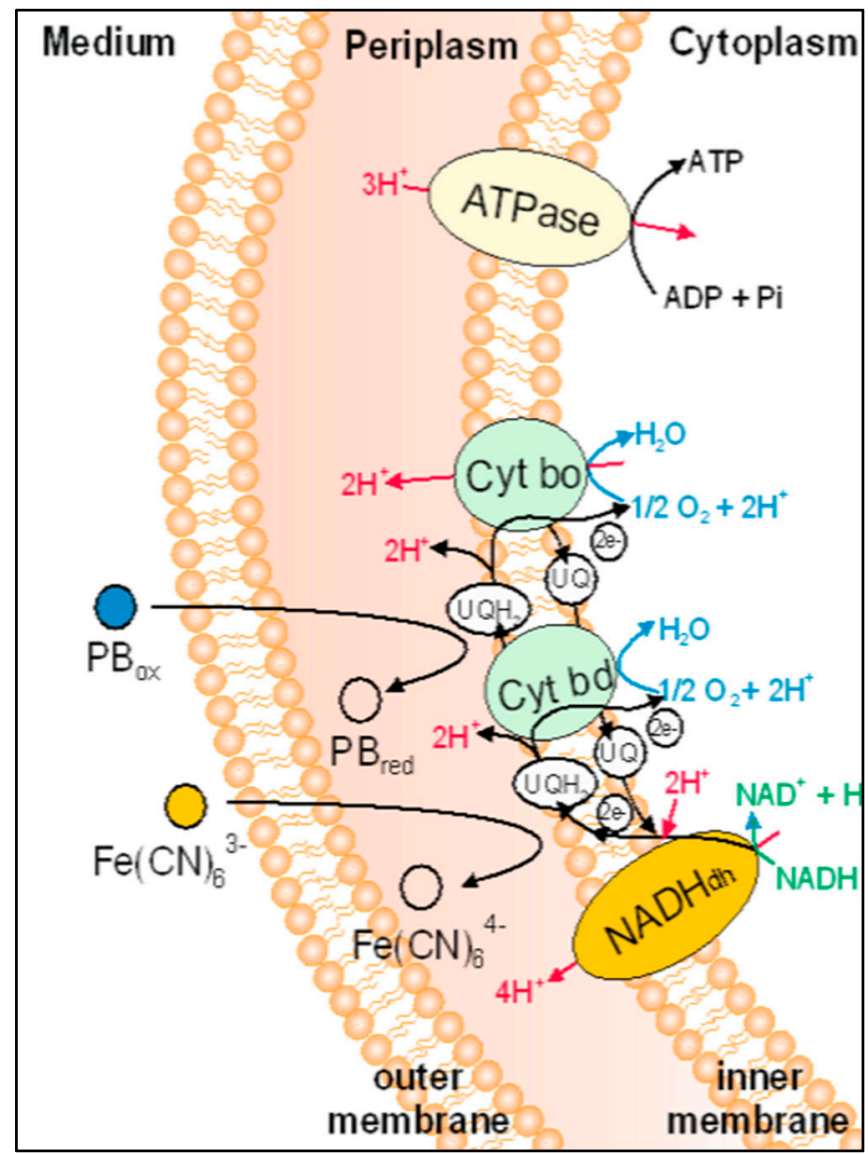

Figure 1. Scheme of the electron transport chain of E. coli.

The smart sensing textile is produced by ultrasonic deposition of PB nanoparticles in polyester cotton fabrics (Figure 2a). After short sonication processes (below $30 \mathrm{~min}$ ) at $0.25 \mathrm{mM} \mathrm{PB}$, sensing molecules are stably entrapped and homogeneously distributed in the matrix of the fabrics (Figure 2b).

Furthermore, the textiles were tested using reducing and oxidizing agents (Figure 3), showing the reversibility of the process. When the textile with Prussian Blue incorporated is in contact with the reducing agent, a change from PB to Prussian White form is showed. However, after oxidizing 
agent addition, unmodified textiles show the reversibility to the PB form in the most part of the textile. This phenomenon could be due to the fact that PB could be partially solved into the medium produced by the insertion of potassium cations into the cubical structure of Prussian Blue.

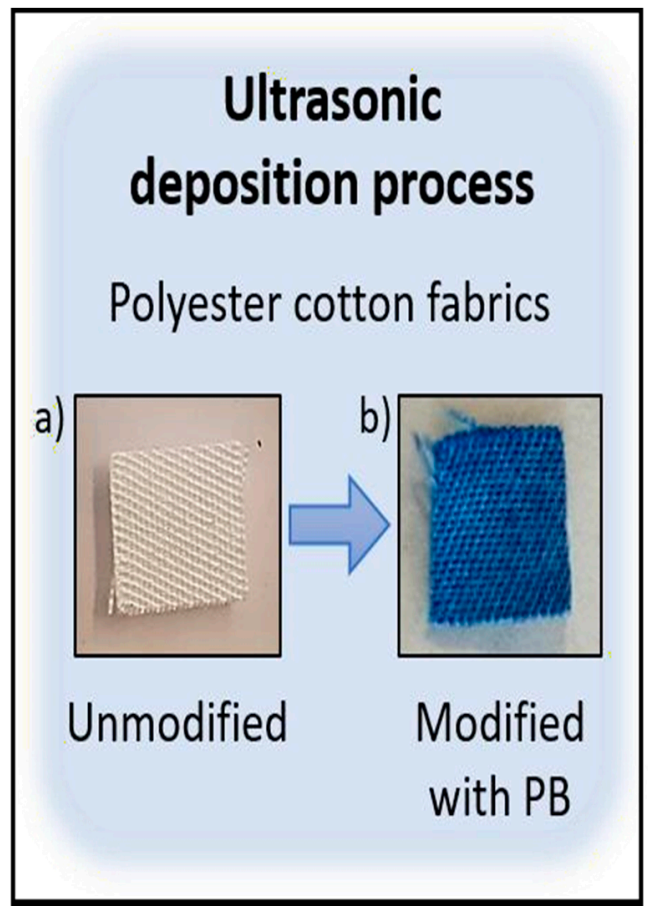

Figure 2. (a) Polyester cotton fabrics unmodified and (b) modified with Prussian Blue $0.25 \mathrm{mM}$ by ultrasonic deposition.

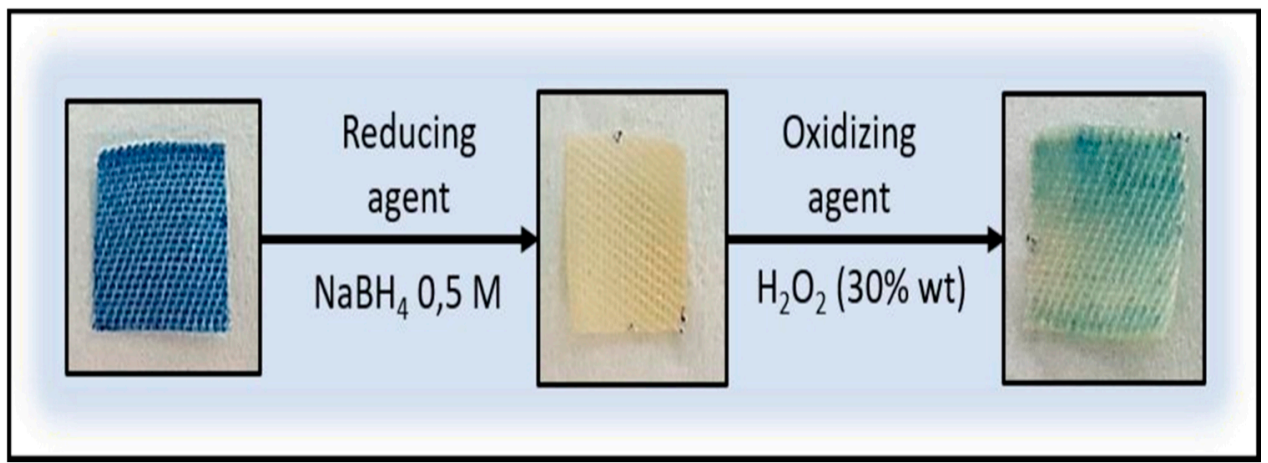

Figure 3. Reversibility assays in the textiles, using as reducing agent $\mathrm{NaBH}_{4} 0.5 \mathrm{M}$ and as oxidizing agent $\mathrm{H}_{2} \mathrm{O}_{2}$ (30\% wt).

To demonstrate the sensing capacity of $\mathrm{PB}$, modified fabrics were incubated with bacterial samples of E. coli (Figure $4 \mathrm{~b}$ ) and S. aureus (Figure 4c) during $24 \mathrm{~h}$, as model gram-negative and grampositive bacteria. Samples in contact with microorganism lost their initial blue colour by the metabolic reduction of both microorganism, obtaining Prussian White, whereas control samples in culture medium remained blue (Figure 4a). 


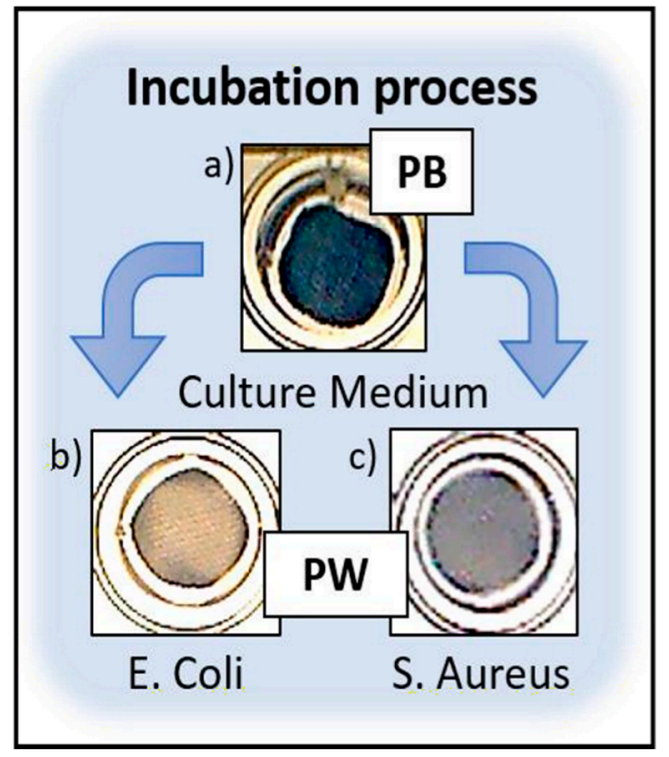

Figure 4. (a) PB modified fabrics in culture medium. (b) Modified samples after $24 \mathrm{~h}$ of incubation with E. coli $\left(5.7 \times 10^{10} \mathrm{CFU} / \mathrm{mL}\right)$ and $(\mathbf{c})$ S. aureus $\left(5.9 \times 10^{10} \mathrm{CFU} / \mathrm{mL}\right)$.

After bacterial assays, reversibility tests were carried out on the textiles with the Prussian White form on them (Figure 5), showing the completely reversion to Prussian Blue after addition of hydrogen peroxide (oxidizing agent).

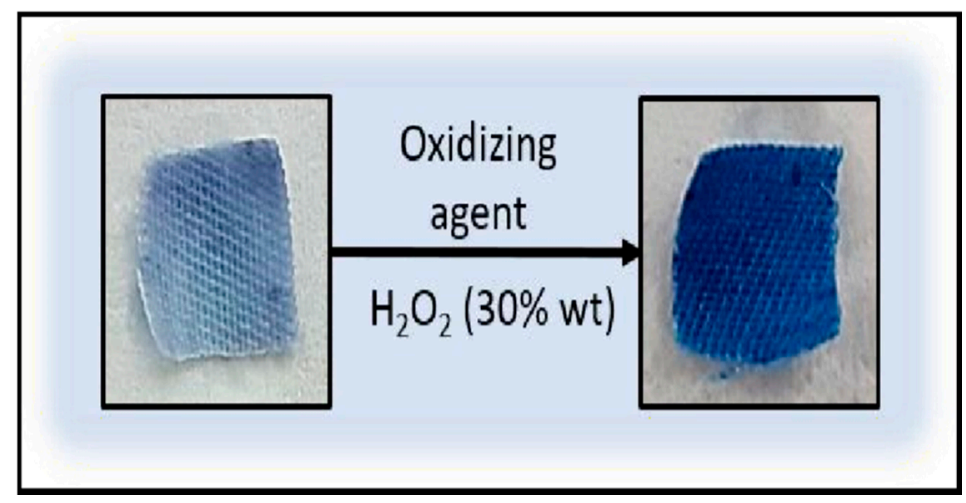

Figure 5. Reversibility assays after $24 \mathrm{~h}$ of bacterial incubation.

Electrochemical and optical assays are currently conducted to understand the dynamics of the process and to evaluate the potential sensing capacity of the smart sensor.

\section{Conclusions}

A smart electrochromic textile sensitive to live bacteria presence in antimicrobial hospital tissues is here proposed. The capacity to detect viable bacteria is based on the use of Prussian Blue as electrochromic compound with a clear reversible change of colour, from PB to Prussian White after reduction caused by an electron transfer process from the reactions involved in the bacterial metabolism. PB nanoparticles are incorporated to polyester cotton fabrics by ultrasonic deposition. Reversibility assay shows a possible redissolution of some PB incorporated into the textile after reduction-oxidation cycles. Textiles in contact with samples of E. coli and S. aureus show full colour change in less than $24 \mathrm{~h}$. After bacterial assays, full blue coloration could be recovered with the oxidation of PW, showing the stability of the PB into the textiles. Finally, it is worthy to note that these smart textiles will not only allow to determine the self-life of the antibacterial compounds but also to improve the control of hospital infections. 
Author Contributions: X.M.-B., G.G., K.I. and A.F.-V. conceived and designed the experiments; Y.A., A.F.-V. and M.D.-G. performed the experiments; X.M.-B., G.G. and T.T. analyzed the data; K.I. and G.G. contributed reagents/materials/analysis tools; A.F.-V., G.G., X.M.-B. and T. T. wrote the paper.

Acknowledgments: This work was supported the European Commission through the project PROTECT (H2020NMBP-PILOT-720851).

Conflicts of Interest: The authors declare no conflict of interest.

\section{References}

1. Khan, H.A.; Baig, F.K.; Mehboob, R. Nosocomial infections: Epidemiology, prevention, control and surveillance. Asian Pac. J. Trop. Biomed. 2017, 7, 478-482.

2. Mao, X.; Yang, L.; Su, X.L.; Li, Y. A nanoparticle amplification based quartz crystal microbalance DNA sensor for detection of Escherichia coli O157:H7. Biosens. Bioelectron. 2006, 21,1178-1185.

3. Shirasu, K. The HSP90-SGT1 Chaperone Complex for NLR Immune Sensors. Annu. Rev. Plant Biol. 2009, 60, 139-164.

4. Maukonen, J.; Mattila-Sandholm, T.; Wirtanen, G. Metabolic Indicators for Assessing Bacterial Viability in Hygiene Sampling Using Cells in Suspension and Swabbed Biofilm. LWT Food Sci. Technol. 2000, 33, 225-233.

5. Platt, J.R. Electrochromism, a Possible Change of Color Producible in Dyes by an Electric Field. J. Chem. Phys. 1961, 34, 862-863.

(C) 2018 by the authors. Licensee MDPI, Basel, Switzerland. This article is an open access article distributed under the terms and conditions of the Creative Commons Attribution (CC BY) license (http://creativecommons.org/licenses/by/4.0/). 